\title{
A Study on Sustainable Design for Indigo Dyeing Color in the Visual Aspect of Clothing
}

\author{
Chih-Chun Lai (1) and Ching-Erh Chang *(1) \\ Graduate Institute of Design Science, Tatung University, Taipei City 104, Taiwan; lai@ttu.edu.tw \\ * Correspondence: cce3056@ms34.hinet.net
}

Citation: Lai, C.-C.; Chang, C.-E. A Study on Sustainable Design for Indigo Dyeing Color in the Visual Aspect of Clothing. Sustainability 2021, 13, 3686. https://doi.org/ $10.3390 /$ su13073686

Academic Editor: Flavio Boccia

Received: 20 February 2021

Accepted: 23 March 2021

Published: 26 March 2021

Publisher's Note: MDPI stays neutral with regard to jurisdictional claims in published maps and institutional affiliations.

Copyright: (c) 2021 by the authors. Licensee MDPI, Basel, Switzerland. This article is an open access article distributed under the terms and conditions of the Creative Commons Attribution (CC BY) license (https:// creativecommons.org/licenses/by/ $4.0 /)$.

\begin{abstract}
Various colors of clothing originating from synthetic dyes are presently causing serious environmental pollution problems, whereas natural dyes extracted from indigo plants help to reduce harm to the environment and extend the sustainable use of clothing. This study focuses on the difference between indigo dyeing colors and the environment on the basis of sustainable design. This study surveyed 105 postgraduates and college students through repeated measurements of ANOVA. The results reveal that light colors are considered to conform to the sustainable spirit more than dark colors in different indigo shades. In fact, a recyclable light-colored indigo-dyed $t$-shirt is beneficial due to its reusability. Indigo-dyed fabric can be decomposed by a variety of microorganisms; however, light-colored indigo dyeing takes a shorter amount of time. Light-colored indigo dyeing is more resource-saving when considering dye, water and electricity costs. The results of the relationship between colors and environmental protection provide scheme references to consumers or industries for clothing collocation of different indigo dyeing colors for a series of blue clothing, and carry out the idea of sustainability and co-existence between clothing and natural resources.
\end{abstract}

Keywords: color; indigo dyeing; sustainable design; clothing

\section{Introduction}

Fast fashion leads the market trend; the use of environmentally harmful chemicals and textile waste accumulation cause the textile industry to remain the second worst polluting industry worldwide [1]. The problem of serious environmental pollution is perceived by people who desire the industry to have a more friendly attitude toward the environment. The use of natural indigo dye is one of many environmentally friendly ways to not only produce special aesthetic qualities, but also give added value to textile production which is extremely difficult to copy, even for the dyers [2]. The chroma and hue of cloth dyed with natural indigo are better than the respective values of cloth dyed with synthetic indigo when cloths are dyed repeatedly [3]. Based on the idea of environmental friendliness, studies applied many methods including the activated carbon (AC) adsorption process to remove the toxicity of dyeing wastewater, as well as the Temkin adsorption isotherm model to separate yeast indigo dye, Diutina rugosa, and improve the color fastness of indigo to the industry standard with indirect electrochemical reduction, so as to deal with environmental crises [4-6]. This current study is interested in discussing the relationship between indigo dyeing colors and the environment. Based on sustainable design, the study further examines different situations involving colors of indigo dye in clothing so as to offer references of color application to indigo-dyed clothing and for the sustainable design of natural resources.

\section{Literature Review}

\subsection{Indigo Dyeing}

According to historical events, indigo plants were cultivated at first by peasants who sailed across the sea from mainland China to Taiwan in 1634. The Netherlands authorities 
cooperated with landlords in the period under the government of the Netherlands in Taiwan in 1639 . However, the indigo industry gradually declined due to the impact of synthetics, soil fertility degradation, other crops affecting indigo plants, "formerly Taiwanese aborigines" encroaching, and local indigo fabrics competing with mainland China at the end of the Qing dynasty. Nevertheless, in Taiwan, workers dyed with fresh indigo mud at that time; the indigo fabrics not only had a durable color, but also had a beautiful sheen of high quality $[7,8]$. In around 1999, the indigo craft began its first step of recovery in Taiwan. Since then, technical guidance, experiences, lecture courses, and special exhibitions on indigo have been conducted continually, progressively popularizing it nationwide. It symbolizes the ongoing tradition of culture and technique, and many different kinds of exquisite commodities have been promoted successfully by many companies up until now [9-11]. This study employed the most widely used color system-namely, the Munsell system - to discuss indigo dyeing. Although indigo dyeing is based on a single color, it can produce a bright blue hue, as well as a variety of levels of intermediate colors [12,13]. The indigo hue produced from the dyeing process is between 5BG and 5PB in the Munsell Color Circle. This study utilized indigo dyeing to produce different chromaticities of blue, so as to explore the differences of indigo dyeing in sustainable design.

Regarding indigo dyeing, the production process includes two parts: indigo dye making and the dyeing process $[8,14]$. Indigo dye-making procedures and processes are shown in Table 1. Furthermore, creations which were dyed from pre-washed fabrics to finished dyeing are shown in Table 2, as follows.

Table 1. Indigo dye making procedures and processes.

\begin{tabular}{|c|c|c|}
\hline Steps & Making Process & Illustration \\
\hline 1. Growing indigo & Growing indigo plants. & $\begin{array}{l}\text { Raw materials come from } \\
\text { natural plants. }\end{array}$ \\
\hline 2. Picking indigo & $\begin{array}{l}\text { Harvesting indigo plants in both June to July and } \\
\text { November to December mornings every year. }\end{array}$ & $\begin{array}{l}\text { Indigo plants picked by } \\
\text { manual labor. }\end{array}$ \\
\hline 3. Soak & $\begin{array}{l}\text { Cutting stems and cleaning them, and then soaking } \\
\text { them in water for about one and a half to two days } \\
\text { until indimuslin appears. }\end{array}$ & Only use water. \\
\hline 4. Oxidation in a vat & $\begin{array}{l}\text { Removing rotted leaves and adding some lime water, } \\
\text { mixing and oxidizing indimuslin with lime by a } \\
\text { pump and water circulating system. It will become } \\
\text { foamy; after two or three hours, the foam disappears, } \\
\text { meaning that the indimuslin has been oxidized. }\end{array}$ & Using lime and electricity. \\
\hline 5. Indigo mud & $\begin{array}{l}\text { Two or three days later, the infant dye needs to be } \\
\text { whipped and some water needs to be added to settle } \\
\text { it again. Two or three days later, the dye needs to be } \\
\text { whipped to obtain the indigo mud. }\end{array}$ & $\begin{array}{l}\text { Waste liquid could be used } \\
\text { for irrigation. }\end{array}$ \\
\hline 6. Indigo dyeing & Put the indigo mud in a vat, and then dip dye fabrics. & $\begin{array}{l}\text { Indigo dyeing is ready } \\
\text { for use. }\end{array}$ \\
\hline
\end{tabular}

Table 2. Making procedures and processes of fabric of indigo dyeing.

\begin{tabular}{ccc}
\hline Steps & Making Process & Illustration \\
\hline $\begin{array}{c}\text { 1. Pre-wash } \\
\begin{array}{c}\text { 2. Selection of dyeing } \\
\text { techniques }\end{array}\end{array}$ & $\begin{array}{c}\text { Indigo dyeing techniques include plain dyeing, } \\
\text { shibori, board indigo dyeing, stencil dyeing, batik, } \\
\text { and discharge dyeing. }\end{array}$ & $\begin{array}{c}\text { Using manul labor, water } \\
\text { and gas. }\end{array}$ \\
\hline $\begin{array}{c}\text { 3. Design and make } \\
\text { 4. Dampen fabric }\end{array}$ & $\begin{array}{c}\text { Design patterns and techniques, and then planning } \\
\text { procedure and process. }\end{array}$ & Making patterns by hand. \\
\hline
\end{tabular}


Table 2. Cont.

\begin{tabular}{|c|c|c|}
\hline Steps & Making Process & Illustration \\
\hline 5. Dyeing & There are two methods: dip dyeing and deep dyeing. & Manual operation. \\
\hline 6. Oxidation & Expose to air for oxidation. & Manual operation. \\
\hline $\begin{array}{l}\text { 7. Repeat dip and } \\
\text { oxidation }\end{array}$ & $\begin{array}{l}\text { Repeat dip and oxidation until fabrics appear } \\
\text { expected color. }\end{array}$ & Manual operation. \\
\hline $\begin{array}{l}\text { 8. Remove } \\
\text { resist-dyeing tools }\end{array}$ & Remove tying thread, rope, popsicle sticks or wax. & Manual removing. \\
\hline 9. Fixation & $\begin{array}{l}\text { Use water as a thinner for white vinegar and dip for } \\
\qquad 5 \mathrm{~min} \text {. }\end{array}$ & $\begin{array}{l}\text { Using white vinegar and } \\
\text { water. }\end{array}$ \\
\hline 10. Clean & Wash with water to clean. & Only water. \\
\hline 11. Dry & Dry the fabrics. & Dry by airing. \\
\hline 12. Iron & Iron the fabrics. & Using electricity. \\
\hline
\end{tabular}

\subsection{Sustainable Design}

In order to solve environmental problems and improve the overall well-being of our living environment, the sustainability of the environment is an important topic. Sustainability is a social and ecological process characterized by the pursuit of common ideals [15], denoting the ability to continue to exist. It refers to the ability of the biosphere and human civilization to co-exist, and it is the process by which human beings maintain changes in a dynamically balanced environment. Whether for systems, exploitation, future development or other changes, these all need to be coordinated to enhance current and future human needs and desires [16]. As ecologists believe that sustainability is achieved through the balance of species and resources in the environment, the consumption of available resources must not be faster than naturally generated resources in order to maintain this balance $[17,18]$. According to the United Nations Document A/42/427, the report of the World Commission on Environment and Development, "Our Common Future" (1987), states that sustainable development is "development that meets the needs of the present without compromising the ability of future generations to meet their own needs" [19]. Sustainable development means striving to balance local and global environments without damaging the natural environment, so as to meet the basic needs of mankind [20].

With the widespread use of synthetic dyes that conform to the economy in time, money and efficiency due to industrialization, the processes of garment dyeing are led by rates. According to statistics, over $7 \times 10^{5}$ tons of synthetic dyes have been produced worldwide every year [21]. The result of rapid industrialization has led to several toxic chemical substances such as dye affecting the environment, causing serious environmental pollution [22]. Sustainable design plays a decisive role in sustainable development. The idea of sustainable design advocates that architectural environments and services of design should conform to the principle of sustainability. The intention of sustainable design is to "eliminate negative environmental impact completely through skillful, sensitive design" [23]. Hence, sustainable design is a necessary step in sustainable development that is harmless to nature, society and the economy by considering the whole lifecycle, integrating all designs into the system, reducing costs and negative effects, and showing different improved effects [24]. Fashion design is one sustainable design category, if clothing uses natural plant dyes that are not only non-toxic and free of health hazards such as skin allergies, but also relieve the environmental load from chemically contaminated water $[25,26]$. Therefore, using eco-friendly, nontoxic, sustainable and renewable natural dyes has become one of several options, including indigo dye extracted from the indigofera plant [27]. To face the current situation, industries are responsible globally; sustainable design that generalizes three common principles can be applied to different industries as follows.

First, recycling means that everyone can reduce their waste and use non-toxic, sustainable or recycled materials as soon as possible, which can be reused continuously in a 
continuous closed cycle, reducing the negative impacts of materials to the minimum. The main materials of indigo-dyed clothing are cotton, linen, silk, or wool. These items can be recycled as fiber or resold, donated, repaired, adapted, or redesigned, depending on how worn out the clothing is. Furthermore, indigo dyeing in Taiwan obtains materials from local sources that are planted and manufactured again and again. The extracted plant residue is able to make compost, and the dyeing water is used for repeated irrigation [28,29].

Second, less-polluting and more recyclable means that materials should come from local or bioregional proximity; materials can be composted through biodegradation and compost recycled to the environment when their usefulness has been exhausted. For indigo, studies have shown that lighter colors have a shorter biodegradation time, and darker colors take longer [30]. Therefore, after clothing with different indigo dyes is recycled, it will inevitably have a different biodegradation time due to the different degrees of chromaticity.

Third and finally, resource-saving means that designers use less energy by considering manufacturing processes and manufacturing low-energy products. As for indigo dyeing-from blue grass to dyes, then to various techniques, and finally, to the finished products-the whole process is performed in the same dyeing vat. Lighter colors require less dyeing time and do not need to consume a lot of water and energy [11,31,32]. Moreover, the production steps can be complicated or simple according to requirements and designs, thus exhibiting good energy efficiency. Regarding dyeing time, dark color fabrics need a longer dyeing time, which allows fabrics to absorb more dye [30]. Therefore, regarding indigo dyeing, lighter colors are more resource-saving.

The usage amount of natural dye has increased on the basis of people's eco-friendly attitude to the environment, due to natural dyes having better biodegradability and generally having higher compatibility with the environment [33]. Consequently, the usage of natural dye has become one of the world's future trends. This study discusses the differences between indigo dyeing colors and the sustainable design of natural resources according to the importance of the sustainable design of indigo dyeing.

\section{Materials and Methods}

\subsection{Indigo Dyeing Experiment and Procedure}

During the research process, the dyeing experiment was performed first, and statistical analysis was performed next through repeated measurements of ANOVA and the Bonferroni post hoc test. Then, differences in the opinions of the participants were discussed.

This study experimented with indigo dyeing according to sustainable design principles, along with recyclable, less-polluting, and resource-saving goals. The fabric for indigo dyeing, the indigo dyeing processes and indigo dyeing colors for this study are as follows. Indigo dyeing fabric: plain-weave cotton fabric.

Indigo dyeing process:

After dyeing, dyed fabrics have to be aerated so that the dye and fiber can be fixed together and appear blue. This process is called "oxidation".

First time: dip for $2 \mathrm{~min}$; oxidation for $3 \mathrm{~min}$.

Second time: dip for $2.5 \mathrm{~min}$; oxidation for $3 \mathrm{~min}$.

Third time: dip for $3 \mathrm{~min}$; oxidation for $3 \mathrm{~min}$.

Cotton fabrics are added for $30 \mathrm{~s}$ each time and are dipped for $6 \mathrm{~min}$ until the 9 th time.

Finally, use water as a thinner for white vinegar and dip for $5 \mathrm{~min}$. The cotton fabrics then need to be washed and dried. Concerning indigo dyeing, Figure 1 shows the experimental procedure for indigo dyeing from 1 to 9 . 


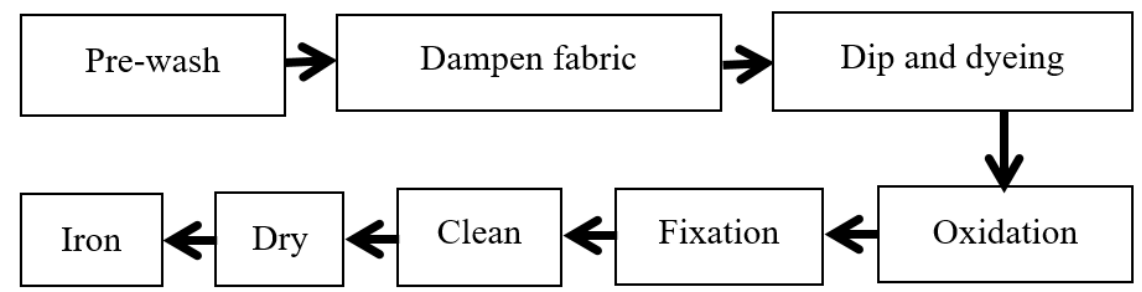

Figure 1. Indigo dyeing experimental procedure.

Color No.1 was dyed first, with dip and oxidation once, while color No.2 was dyed a second time, with dip and oxidation twice; color No.9 was dyed a ninth time, with dip and oxidation nine times, as shown in Figure 2, which displays nine indigo-dyed colors in total.

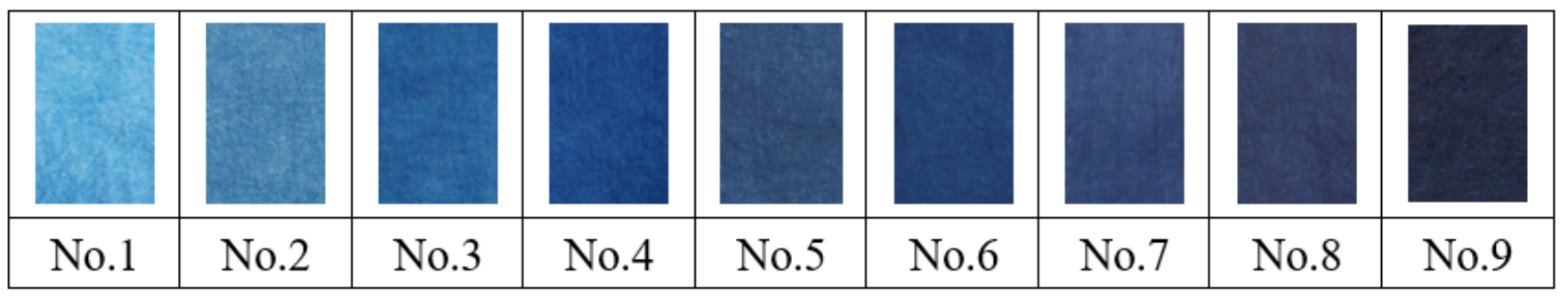

Figure 2. Indigo dye making procedures and processes here.

\subsection{Research Framework}

The values of the Munsell color system range from the bottom, being black (0), to the top, being white (10). The intermediate phases cover nine gray colors [34]. Indigo dye is a single color; however, it is able to produce different neutral blues and is generally able to be applied to the indigo dyeing of clothing. This study discusses the differences between indigo dye colors and sustainable design principles.

\subsection{Research Hypothesis}

This study took color as the independent variable and sustainable design as the dependent variable to explore whether there are significant differences between different indigo dyes, in terms of sustainable design principles such as recycling, low pollution, and the saving of resources. Indigo-dyed fabrics are mainly natural fibers such as cotton, hemp, silk, and wool. After recycling, they can be regenerated into renewable fibers, or resold, donated, repaired, transformed, or redesigned. For the natural indigo, the dye is taken from local materials and can be planted and produced sustainably [28]. The extracted plant residue can be composted, and the wastewater generated during the indigo dye collection process can also be used as irrigation for recycling [29]. As a result, it is sustainable. Therefore, $\mathrm{H} 1$ is proposed as follows.

Hypothesis 1 (H1). The opinion of respondents significantly differs for indigo-dyed t-shirts with different colors regarding sustainable design principles and recycling goals.

For indigo, studies have shown that lighter colors have a shorter biodegradation time, and darker colors take longer [30]. Therefore, after the indigo-dyed clothing of different colors is recycled, it would inevitably have a different biodegradation time due to the different degrees of chromaticity. Therefore, $\mathrm{H} 2$ is proposed as follows.

Hypothesis 2 (H2). The opinion of respondents significantly differs for indigo-dyed $t$-shirts with different colors regarding sustainable design principles, and less-polluting goals. 
As for indigo dyeing, from blue grass to dyes, to various techniques, and finally to the finished products, the whole process is performed in the same dyeing vat. Lighter colors have shorter dyeing times, and darker colors have greater dyeing times. They do not need to consume a lot of water and energy, and so they have good energy efficiency. In addition, darker colors require longer dyeing times, which also increases the amount of dye absorbed by the fabric [19]. Therefore, H3 is proposed as follows.

Hypothesis 3 (H3). The opinion of respondents significantly differs for indigo-dyed $t$-shirts with different colors regarding sustainable design principles, and resource-saving goals.

\subsection{Data Collection}

The participants in this study were postgraduates and undergraduates enrolled at Tatung University in Taipei. This study adopted a convenience sampling method, because students with a design background may have more unique views on colors versus students with other backgrounds. The researcher used convenience sampling, and the total sample in this study comprised 105 students, $75.2 \%$ of whom were female and $24.8 \%$ of whom were male. The average age of the participants was 26.61 years.

\subsection{Process of Visual Experiment}

First, fabric samples of indigo dye were used for $t$-shirts in this study. The $t$-shirt had a round neck and short sleeves, which is considered to be leisurewear in summer and suitable for both males and females. This study drew a t-shirt and set up a questionnaire.

Regarding the size of the indigo dye fabric samples being $14 \mathrm{~cm} \times 11 \mathrm{~cm}$, observers with normal color vision, as tested by the Ishihara Color Test, were selected according to their opinions. This study invited observers to enter a classroom and be near windows, in order to experiment with lighting during the daytime from morning to noon, as the light near the window is similar to CIE (International Commission on Illumination, abbreviated CIE) standard illuminant D65, as in Figure 3 [35]. All fabric samples of the indigo dyes were put on gray paper. Only one fabric sample was put on a desk rather than gray paper for observers' comparison with the questionnaire.

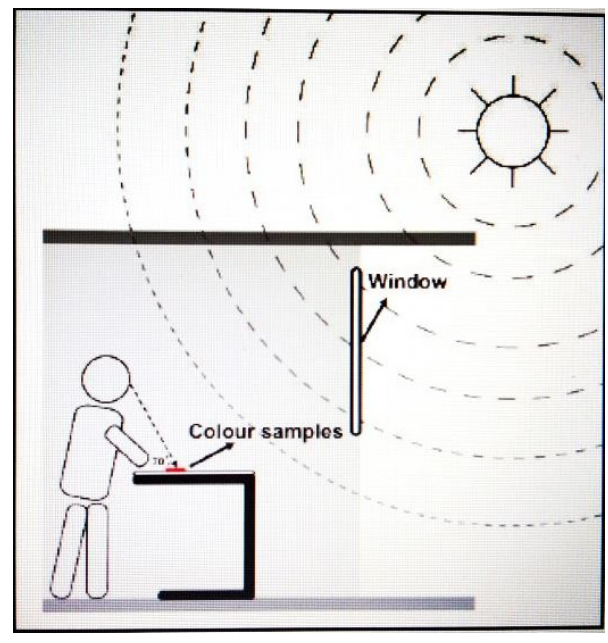

Figure 3. Experimental situation here.

\subsection{Instrument}

The survey questionnaire in this study included an indigo dyeing color scale and demographic data for a total of 30 questions. There were 9 questions concerning contents in the indigo dyeing color scale, i.e., there were 9 articles of $t$-shirts with different blue colors. Each t-shirt displayed blue in uniform color. Each pattern involved three items, which were modified from Bianchi and Birtwistle [36] to better meet the research purposes of this study. Demographic data on the participants included gender, age, and education. 


\subsection{Data Analysis}

In terms of data analysis, the participants in this study rated each picture using a five-point Likert-type scale, ranging from " 5 (strongly agree)" to " 1 (strongly disagree)". The data collected were entered into a database and analyzed using the SPSS 22.0 statistical software package. The results went through repeated measurements of ANOVA and Bonferroni's post hoc test to check whether there was a significant difference between indigo dyeing and sustainable design principles. The results appear in the accompanying tables.

\section{Results}

In the statistical analysis, repeated measurements of ANOVA and the Bonferroni post hoc test were used on participants' opinions on reducing the environmental impacts of recyclable indigo-dyed t-shirts. They are shown in Table 3, which reveals that according to the Mauchly Spherical test, the opinions of participants were significantly different $(\mathrm{F}=42.837, p=0.000<0.001)$, revealing that the Spherical test had been violated and the result showed forward bias; therefore, the $\mathrm{F}$ tests should be adjusted by GeisserGreenhouse (G-G). After adjustment, $p=0.000<0.001$, which means that regarding recyclable indigo-dyed $\mathrm{t}$-shirts, the darker the colors, the less the environmental protection. Furthermore, according to trend analysis $(p=0.000<0.001)$, nine colors show linear relationships that indicate that the degree of benefit to the environment of the nine colors decreases gradually seriatim from the light color No.1 $(\mathrm{M}=3.95)$ to the dark color No.9 $(\mathrm{M}=2.71)$. Consequently, Hypothesis 1 is supported.

The results of less-polluting indigo-dyed t-shirts are shown in Table 3, which indicates the opinions of participants about the nine t-shirts which used natural indigo plant dyes that were friendly to the environment. In Table 3, less pollution-related results reveal differences among the opinions of participants about different colors $(\mathrm{F}=56.233, p=0.000$ $<0.001$ ) according to the Mauchly Spherical test that indicates the Spherical test had been violated and the result showed forward bias; therefore, the $\mathrm{F}$ tests should be adjusted by Geisser-Greenhouse (G-G). After adjustment, $p=0.000<0.001$, indicating the opinions of participants about indigo-dyed $t$-shirts as being less polluting. There are differences in the different shades of colors regarding biodegradation. In addition, according to trend analysis $(p=0.000<0.001)$, nine colors show linear relationships that indicate the degree of benefit to the environment, decreasing gradually seriatim from the light color No.1 $(\mathrm{M}=4.22)$ to the dark color No.9 $(\mathrm{M}=2.79)$. Consequently, Hypothesis 2 is supported.

Regarding the results of resource-saving, participants' opinions of the nine indigodyed $\mathrm{t}$-shirts are shown in Table 3. The results reveal differences among the opinions of participants about the different colors $(\mathrm{F}=60.464, p=0.000<0.001)$ according to the Mauchly Spherical test, indicating that the Spherical test had been violated and the result showed forward bias; therefore, the F tests should be adjusted by Geisser-Greenhouse $(\mathrm{G}-\mathrm{G})$. After adjustment, $p=0.000<0.001$, indicating the opinions of participants about indigo-dyed t-shirts in regard to resource-saving; there are differences concerning resource use, including dye consumption, dyeing water and electricity, in the different shades of colors. Moreover, trend analysis $(p=0.000<0.001)$ reveals that the nine colors show linear relationships and indicates that the degree of benefit to the environment of the nine colors decreased gradually seriatim from the light color No.1 $(\mathrm{M}=3.97)$ to the dark color No.9 $(\mathrm{M}=2.48)$. Consequently, Hypothesis 3 is supported. 
Table 3. Relationship between indigo dyeing and being recyclable, less-polluting, and resourcesaving.

\begin{tabular}{|c|c|c|c|}
\hline \multirow{2}{*}{ Color } & Recyclable & Less-Polluting & Resource-Saving \\
\hline & M (SD) & M (SD) & M (SD) \\
\hline 1 & $3.95(0.92)$ & $4.22(0.72)$ & $3.97(0.79)$ \\
\hline 2 & $3.90(0.80)$ & $4.06(0.77)$ & $3.83(0.73)$ \\
\hline 3 & $3.63(0.92)$ & $3.86(0.89)$ & $3.61(0.84)$ \\
\hline 4 & $3.70(0.91)$ & $3.77(0.97)$ & $3.47(0.93)$ \\
\hline 5 & $3.41(1.05)$ & $3.51(1.09)$ & $3.28(1.00)$ \\
\hline 6 & $3.30(1.14)$ & $3.39(1.18)$ & $3.19(1.08)$ \\
\hline 7 & $3.01(1.24)$ & $3.10(1.32)$ & $2.73(1.19)$ \\
\hline 8 & $2.90(1.28)$ & $2.97(1.33)$ & $2.58(1.21)$ \\
\hline 9 & $2.71(1.34)$ & $2.79(1.41)$ & $2.48(1.30)$ \\
\hline $\mathrm{F}$ & 42.837 & 56.233 & 60.464 \\
\hline$p$ & $0.000^{* * *}$ & $0.000^{* * *}$ & $0.000^{* * *}$ \\
\hline Post-Hoc & $\begin{array}{c}1,2>3,5,6,7,8,9 \\
3>6,7,8,9 \\
4>5,6,7,8,9 \\
5,6>7,8,9 \\
7,8>9\end{array}$ & $\begin{array}{c}1>3,4,5,6,7,8,9 \\
2>4,5,6,7,8,9 \\
3,4>5,6,7,8,9 \\
5,6>7,8,9 \\
7>9\end{array}$ & $\begin{array}{c}1,2>3,4,5,6,7,8,9 \\
3>5,6,7,8,9 \\
4>6,7,8,9 \\
5,6>7,8,9\end{array}$ \\
\hline$p$ Trend & $0.000^{* * *}$ & $0.000^{* * *}$ & $0.000 * * *$ \\
\hline
\end{tabular}

\section{Discussion}

Concerning the nine recyclable indigo-dyed t-shirts which benefit the environment, the results show significant differences among different colors in the opinions of participants, and that the scores decrease linearly. Maybe the reason for this is that the application of light colors would be easier than dark colors in influencing participants' opinions; for example, a dark color would be chemically bleached because of fading or color unevenness if clean recyclable t-shirts need to be re-dyed [37]; however, light-colored clothes could be dyed directly if recyclable $t$-shirts are to be continually reused in a closed cycle. Hence, light-colored t-shirts have a higher score and the darker the color, the lower the score, revealing a linear decrease.

Second, regarding the nine less-polluting indigo-dyed t-shirts, the results reveal differences in participants' opinions about different colors polluting the environment. 
Previous studies showed that cotton is not resistant to microorganisms-white cotton fabrics clearly had the most severe degradation after 28 days of burial-however, ordinary cotton fabric biodegradation takes 40 days [38-40]. In other words, the time light-colored cotton fabrics take is shorter than dark-colored cotton fabrics, which take a longer time, i.e., they decompose more quickly. Consequently, participants' opinions showed that No.1, the light color t-shirt, obtained the highest score; the darker the color, the more the score decreased gradually, revealing a linear decrease.

Finally, there are different opinions among the participants about the degree of resource-saving of indigo dyed t-shirts. However, the participants agreed that No.1, light-colored t-shirt, is the most resource-saving, while the darker colors in order signified more resource consumption, revealing a linear decrease. In short, the participants agreed that the light-colored $t$-shirts are more resource-saving than the dark-colored ones. The experimental procedure for indigo dyeing shows that light-colored indigo-dyed fabric had a fewer number of dipping times than dark colors, and dark color fabrics also absorbed more dye. The number of dipping times is closely linked with consumed resources such as water and electricity; the fewer the number of dipping times, the lower the consumption of resources, and vice versa. Consequently, the results are consistent with the studies of Kant [31], Lee [11], and Nunes, Matias and Catalão [32]. Indigo dyeing includes the processes from plants to dye, different techniques, and finally, to the finished product; all these steps do not deplete a large amount of water and electricity.

\section{Conclusions}

Concerning indigo dyeing, light colors are considered to conform to the sustainable spirit more than dark colors. This study generalizes a conclusion from the sustainability principle: recyclable, less-polluting, and resource-saving clothing. The recyclable light-colored indigo-dyed t-shirts offer benefits via reuse. Indigo-dyed fabrics can be decomposed by a variety of microorganisms; light-colored indigo dyeing takes a short time, and dark-colored indigo dyeing takes a long time. In terms of resource-saving, light-colored indigo dyeing is greater when considering dye, water and electricity costs.

Furthermore, consumers should pay more attention to issues related to dyes. In order to contribute to the environment, consumers can increase their attention to the issue of clothing dyes. A designer who is designing a t-shirt can now estimate the degree of impact of both dye source and light and shade at the same time in the field of fashion design, and carry out the idea of sustainability and co-existence between clothing and natural resources. For fashion-related industries, a study of 288 Polish consumers found that women paid more attention to the fit and style of clothing, but did not give consideration to purchasing sustainable products [41]. Therefore, this research calls attention to environmental sustainability issues, in order to formulate corporate sustainable development visions as well as short-term, medium-term, and long-term goals, evaluate sustainable business strategies, and actively plan and implement them with the goal of injecting the spirit of sustainability into a company and helping to make sustainable fashion enter the broader market.

This study only discussed cloth with natural fiber components, and did not compare colors for different fiber components. At the same time, this study only took color as the independent variable, and other possible variables, such as fashion trends and sustainable designs of clothing, were not discussed. Therefore, future researchers can conduct further discussions on related variables.

Author Contributions: C.-E.C. has made substantial contributions to the conception and design, acquisition of data and analysis and interpretation of data. C.-C.L. was involved in drafting the manuscript and revising it critically for important intellectual content. Both authors have read and agreed to the published version of the manuscript.

Funding: This research received no external funding. 
Institutional Review Board Statement: Ethical review and approval were waived for this study, due to the nature of the research where all the respondents were reached to the university and they voluntary took part in this research to express their opinion.

Informed Consent Statement: All the respondents were informed about the use of research data and the statement "By filling this questionnaire you agree that the information provided will be anonymously used in the research. You can stop filling the form if you feel that you do not wish to answer any of questions".

Data Availability Statement: The data that support the findings of this study are available from the corresponding author upon reasonable request.

Conflicts of Interest: The authors declare no conflict of interest.

\section{References}

1. Ma, Y.; Rosson, L.; Wang, X.; Byrne, N. Upcycling of waste textiles into regenerated cellulose fibres: Impact of pretreatments. J. Text. Inst. 2019, 111, 630-638. [CrossRef]

2. D'cruz, A. Adding an eco-friendly colour to the world. Chem. World 2012, 10, 40-41. Available online: https://www.researchgate. net/profile/Andrea_Sandra_Christine_Dcruz/publication/257033508_Insight_and_Outlook-Natural_Dyes/links/00b7d524 db5de1c18e000000.pdf (accessed on 9 April 2020).

3. Kawahito, M.; Urakawa, H.; Ueda, M.; Kajiwara, K. Color in Cloth Dyed with Natural Indigo and Synthetic Indigo. Sen'i Gakkaishi 2002, 58, 122-128. [CrossRef]

4. GilPavas, E.; Correa-Sanchez, S. Assessment of the optimized treatment of indigo-polluted industrial textile wastewater by a sequential electrocoagulation-activated carbon adsorption process. J. Water Process. Eng. 2020, 36, 101306. [CrossRef]

5. Bankole, P.O.; Adekunle, A.A.; Obidi, O.F.; Olukanni, O.D.; Govindwar, S.P. Degradation of indigo dye by a newly isolated yeast, Diutina rugosa from dye wastewater polluted soil. J. Environ. Chem. Eng. 2017, 5, 4639-4648. [CrossRef]

6. Yi, C.; Tan, X.; Bie, B.; Ma, H.; Yi, H. Practical and environment-friendly indirect electrochemical reduction of indigo and dyeing. Sci. Rep. 2020, 10, 4927-4928. [CrossRef]

7. Hsiao, C.F. Sowing the seed of indigo dye: A survey of indigo dyeing projects organized by NTCRI. Taiwan Crafts 2014, 54, 24-29. Available online: https://mocfile.moc.gov.tw/ntcrihistory/ebook/978b6jnes_f.pdf (accessed on 9 April 2020).

8. Lin, C.M.; Lin, C.H.; Cheng, T.H. The application of indigo dyeing pattern design in clothing-take batik as example. J. Hwa Gang Text. 2017, 24, 66-71. Available online: http:/ /www.jhgt.org.tw/pdf/jhgt-24.2(66-71)(2017-02).pdf (accessed on 10 April 2020).

9. Chen, J.L. Indigo dyeing in Sanshia: A 10 years' retrospect. Taiwan Crafts 2009, 34, 82-85. Available online: https://mocfile.moc. gov.tw/ntcrihistory / ebook/409ocOX_f.pdf (accessed on 9 April 2020).

10. Hsu, C.I.; Yen, H.Y.; Lin, R. Introducing co-learning and co-creating to revive local craftsmanship: An experimental study on indigo dyeing craftsmanship in Sanxia, Taiwan. J. Arts Humanit. 2018, 7, 68-78. Available online: https: / /www.theartsjournal. org/index.php/site/article/view/1519 (accessed on 10 April 2020).

11. Lee, J.C. Dyeing art of Taiwan, living traces of our land: Itti-natural dye color research. Taiwan Crafts 2009, 70, 42-45. Available online: https: / / mocfile.moc.gov.tw / files / 201809/b5fdf662-3979-4879-a000-1340c2b805ea.pdf (accessed on 9 April 2020).

12. Dharma Trading Co. How to Dye with Natural Indigo. 2015. Available online: https://www.dharmatrading.com/information/ how-to-dye.html (accessed on 13 June 2020).

13. Ellis, C. Indigo Dyeing: Time and Patience. 2018. Available online: https://blog.ellistextiles.com/2018/01/22/indigo-dyeingtime-and-patience/ (accessed on 11 June 2020).

14. Wu, H.M. Indigo fashion: Zhuo Ming-bang's Zhuo Ye Cottage. Taiwan Crafts 2013, 51, 56-59. Available online: https:/ / mocfile. moc.gov.tw/ntcrihistory / ebook/4206oE_f.pdf (accessed on 17 May 2020).

15. Wandemberg, J.C. Sustainable by Design; CreateSpace Independent Publishing Platform: Seattle, WA, USA, 2015; ISBN 9781516901784.

16. Brauer, C. Paths to Sustainability: Creating Connections through Place-Based Indigenous Knowledge. Master's Thesis, Concordia University, Montreal, QC, Canada, 2017.

17. Chaudhary, S.; Mehra, R.; Head, E.E. Role of globalized approach for sustainability development in human life. People Int. J. Soc. Sci. 2018, 4, 1497-1507. [CrossRef]

18. Davies, N. Using Bacteria to Decolorize Textile Wastewater. AATCC Rev. 2017, 17, 32-37. [CrossRef]

19. United Nations World Commission on Environment and Development (WCED). Our Common Future Report. 1987. Available online: https:/ / www.encyclopedia.com/environment/energy-government-and-defense-magazines/united-nations-worldcommission-environment-and-development-wced-our-common-future-report-1987 (accessed on 20 July 2019).

20. Robert, K.W.; Parris, T.M.; Leiserowitz, A.A. What is Sustainable Development? Goals, Indicators, Values, and Practice. Environ. Sci. Policy Sustain. Dev. 2005, 47, 8-21. [CrossRef]

21. Chequer, F.M.D.; Oliveira, G.A.R.; Ferraz, E.R.A.; Cardoso, J.C.; Zanoni, M.V.B.; de Oliveira, D.P. Textile dyes: Dyeing process and environmental impact. In Eco-Friendly Textile Dyeing and Finishing; Gunay, M., Ed.; IntechOpen: London, UK, 2013 ; pp. 151-176. ISBN 978-953-51-0892-4. Available online: https://books.google.com.tw/books?hl=zh-TW\&lr=\&id=IGOfDwAAQBAJ\&oi= 
fnd\&pg=PR9\&dq=ISBN:+978-953-51-0892-4\&ots=zywn9ILcFW\&sig=0d8Ruz3yKh4VR_bVMFweIB1qhmk\&redir_esc=y\#v= onepage\&q=ISBN\%3A\%20978-953-51-0892-4\&f=false (accessed on 22 May 2020).

22. Dhanjal, N.I.K.; Mittu, B.; Chauhan, A.; Gupta, S. Biodegradation of Textile Dyes Using Fungal Isolates. J. Environ. Sci. Technol. 2013, 6, 99-105. [CrossRef]

23. McLennan, J.F. The Philosophy of Sustainable Design, 1st ed.; Ecotone Publishing Company LLC: London, UK, 2004; pp. 1-8. ISBN 0-9749033-0-2. Available online: https:/ /books.google.com.tw /books?hl=zh-TW\&lr=\&id=-Qjadh_0IeMC\&oi=fnd\&pg=PR1 $5 \& \mathrm{dq}=$ The + philosophy+of+sustainable+design\&ots=UtrMG0LkjL\&sig=9LAj5ocCujQvTcaUmwT9uAf09eM\&redir_esc=y\#v= onepage \&q=The \%20philosophy $\% 20$ of\%20sustainable \%20design\&f=false (accessed on 30 March 2020).

24. Blizzard, J.L.; Klotz, L.E. A framework for sustainable whole systems design. Des. Stud. 2012, 33, 456-479. [CrossRef]

25. Bechtold, T.; Turcanu, A.; Ganglberger, E.; Geissler, S. Natural dyes in modern textile dyehouses-How to combine experiences of two centuries to meet the demands of the future? J. Clean. Prod. 2003, 11, 499-509. [CrossRef]

26. Kumar, C.; Dhinakaran, M. Extraction and application of natural dyes from orange peel and lemon peel on cotton fabrics. Int. Res. J. Eng. Technol. 2017, 4, 237-238. Available online: https://www.irjet.net/archives/V4/i5/IRJET-V4I541.pdf (accessed on 5 June 2020).

27. MIAH, M.; Telegin, F.; Rahman, M. Eco-friendly dyeing of wool fabric using natural dye extracted from onion's outer shell by using water and organic solvents. Int. Res. J. Eng. Technol. 2016, 3, 450-467. Available online: https://www.irjet.net/archives/V3 /i9/IRJET-V3I983.pdf (accessed on 1 June 2020).

28. Adeel, S.; Rehman, F.-U.; Rafi, S.; Zia, K.M.; Zuber, M. Environmentally Friendly Plant-Based Natural Dyes: Extraction Methodology and Applications. Plant Hum. Health 2019, 2, 383-415. [CrossRef]

29. Bektaş, I.; Karaman, Ş.; Dıraz, E.; Çelik, M. The role of natural indigo dye in alleviation of genotoxicity of sodium dithionite as a reducing agent. Cytotechnology 2016, 68, 2245-2255. [CrossRef]

30. Vučković, N.; Kodrić, M.; Nikodijević, M.; Đorđević, D. Modeling of the linen fabric dyeing after previous preparation. Adv. Technol. 2018, 7, 68-72. [CrossRef]

31. Kant, R. Textile dyeing industry an environmental hazard. Nat. Sci. 2012, 4, 22-26. [CrossRef]

32. Nunes, L.; Matias, J.; Catalão, J. Analysis of the use of biomass as an energy alternative for the Portuguese textile dyeing industry. Energy 2015, 84, 503-508. [CrossRef]

33. Kulkarni, S.; Bodake, U.; Pathade, G. Extraction of natural dye from chili (capsicum annum) for textile coloration. Univers. J. Environ. Res. Technol. 2011, 1, 58-63. Available online: http://www.environmentaljournal.org/1-1/ujert-1-1-8.pdf (accessed on 17 May 2020).

34. Malacara, D. Color vision and colorimetry: Theory and applications. Color Res. Appl. 2002, 28, 77-78. [CrossRef]

35. Gong, S.M.; Lee, W.Y. Colour preference model for elder and younger groups. J. Int. Color Ass. 2017, 18, 33-42. Available online: http:/ / www.aic-colour.org/journal.htm (accessed on 29 May 2020).

36. Bianchi, C.; Birtwistle, G. Consumer clothing disposal behavior: A comparative study. Int. J. Consum. Stud. 2012, 36, 335-341. Available online: https:/ / eprints.qut.edu.au/47708/2/Paper_IJCS_\%2528final_version_180411\%2529-1.pdf (accessed on 9 June 2020). [CrossRef]

37. Mundkur, S.; Dedhia, E. Supply chain for second-hand clothes in mumbai. Text. Value Chain 2012, 1, 57-58. Available online: https://www.researchgate.net/profile/S_Mundkur/publication/259452417_\T1 \textquoterightWaste_Management_and_ Supply_Chain_for_Second-hand_Clothes_in_Mumbai \T1 \textquoteright_a_research_article_published_in_Textile_Value_ Chain_Volume_1_Issue_3_October-December_2012_ISSN_No_2278-8972_Pp_57-58/links/555062d108ae956a5d24bd13.pdf (accessed on 8 June 2020).

38. Arshad, K.; Skrifvars, M.; Vivod, V.; Valh, J.; Vončina, B. Biodegradation of Natural Textile Materials in Soil. Tekstilec 2014, 57, 118-132. [CrossRef]

39. Chen, H.-L.; Cluver, B. Biodegradation and mildew resistance of naturally colored cottons. Text. Res. J. 2010, 80, 2188-2194. [CrossRef]

40. Warnock, M.; Davis, K.; Wolf, D.; Gbur, E. Soil burial effects on biodegradation and properties of three cellulosic fabrics. Am. Assoc. Text. Chem. Colorists Rev. 2011, 11, 53-57. Available online: https://www.researchgate.net/publication/287919000_Soil_ burial_fefects_on_biodegradation_and_properties_of_Three_cellulosic_fabrics (accessed on 11 June 2020).

41. Rahman, O.; Koszewska, M. A study of consumer choice between sustainable and non-sustainable apparel cues in Poland. J. Fash. Mark. Manag. Int. J. 2020, 24, 213-234. [CrossRef] 